\title{
Simulation Studies Relating to Rudder Roll Stabilization of a Container Ship Using Neural Networks
}

\author{
MUKHTIAR ALI UNAR*, DAVID J MURRAY-SMITH**, SHEHNILA ZARDARI***, AND \\ EUAN W. MCGOOKIN**
}

RECEIVED ON 07.05.2018 ACCEPTED ON 17.08.2018

\begin{abstract}
RRS (Rudder Roll Stabilization) of Ships is a difficult problem because of its associated non-linear dynamics, coupling effects and complex control requirements. This paper proposes a solution of this stabilization problem that is based on an ANN (Artificial Neural Network) controller. The controller has been trained using supervised learning. The simulation studies have been carried out using MATLAB and a non-linear model of a container ship. It has been demonstrated that the proposed controller regulates heading and also controls roll angle very successfully.
\end{abstract}

Key Words: Rudder Roll Stabilization, Ship Control, Artificial Neural Networks, Ship Steering.

\section{INTRODUCTION}

T

The application of ANNs to ship control systems is not a new topic. The feasibility of using ANNs for a ship steering control system was first studied by Endo et. al. [1] and Pugh [2]. Richter and Burns [3] developed an ANN which behaved like a conventional PID (Proportional Integral Derivative) controller. Witt et. al. [4] developed a track-keeping ANN controller for ship guidance. Burns [5] developed an ANN controller which behaved optimally at different sea states. Simensen and Murray-Smith [6] trained their ship steering controller by using control laws developed on the basis of feedback linearization controllers. All the above investigations were based on off-line training of MLP (Multilayer Perceptron) Networks. These networks are also called BP (BackPropagation) type networks. An on-line trained MLP network was first proposed by Zhang et. al. [7]. An alternative approach involving the use of RBF (Radial Basis Function) Networks was first reported by Unar and Murray-Smith [8-9] and the use of recurrent NNs has also been investigated [10-11]. Recent work has been based either on MLP networks [12-13], RBF networks [14-16] or on a combination of neural networks and fuzzy logic [1719]. It has been found that feedforward neural networks (MLP as well as RBF) are more suitable than recurrent networks for control applications. In all of the above mentioned work, ANNs have been used as coursechanging or course-keeping/track-keeping controllers. This paper presents a neural network controller which controls the course as well as the roll response of a ship simultaneously. In other words, it behaves as a RRS.

Authors E-Mail: (mukhtiar.unar@faculty.muet.edu.pk, david.murray-smith@glasgow.ac.uk, shehnilaz@neduet.edu.pk, euan.mcgookin@glasgow.ac.uk)

* Department of Computer Systems Engineering, Mehran University of Engineering \& Technology, Jamshoro, Pakistan.

** School of Engineering, University of Glasgow, Glasgow, Scotland, UK

*** Department of Computer Science \& Software Engineering, NED University of Engineering \& Technology, Karachi, Pakistan.

This is an open access article published by Mehran University Research Journal of Engineering and Technology, Jamshoro under the CC by 4.0 International License. 
Roll is one of the most critical ship motions because of the possibility of extremely large amplitudes and even situations leading to a capsize. Roll dynamics is also important for offshore barges in determining the loads on deck cargo. Large roll motions not only affect the comfort and efficiency of crew members but also the accuracy of electrical mechanisms and the accuracy of control for the ship course [20].

Some devices such as bilge keels, anti-roll tanks, gyroscopic stabilizers, moving weights and fins [21-23] can be used to reduce the roll motion but they increase the cost, occupy useful space and increase the overall weight of the ship. Also the speed and overall performance of the vessel may be affected because of these additional appendages [24]. Since every ship has a steering system, the employment of an RRS to simultaneously control the roll and heading motions is a cost effective approach and improves the ship's capabilities to perform assigned tasks in rough weather conditions. Moreover, the RRS has approximately the same effectiveness as can be achieved with the fin stabilizers [22].

\section{PREVIOUS WORK ON RUDDER ROLLSTABILISATION}

The non-linear behavior of ship roll motion has been the subject of extensive research since the mid of $19^{\text {th }}$ century, pioneered by the work of Froude [25]. However, Chadwick [26] was among the first to investigate the roll stabilization problem from control point of view. He discussed in detail the possible inputs for roll stabilization systems and proposed a fin-roll stabilization system which was essentially a proportional controller. The idea of using the rudder as a roll stabilizer was first suggested by Taggart [27] who observed excessive roll motions induced by the rudder during sea trials. Among the earliest RRS systems were linear controllers proposed by Carley and Duberley [28], Carley [29], Cowley and Lambert [30], and Lloyd [31] in the early 1970s. As the characteristics of RRS are highly nonlinear those simple linear controllers did not show much success. Most probably, the first successful full scale trials were reported by Baitis [32]. In the 1980s and1990s, significant contributions were made by a number of researchers including Van Amerongen et. al. [33-34], Kallstrom et. al. [35-36], Blanke et. al. [37-39] and Lauvdal and Fossen [40-41]. A detailed review of their work can be found in Perez [42]. They emphasized that, due to the non-linear nature of the problem, modern robust control methodologies should be used, rather than simple PID type controllers. During the past 30 years, $\mathrm{H}_{\infty}$ [43-44], Gain Scheduling Control [41], Quantitative Feedback Control [45], Model Predictive Control [46], $\mu \_$Synthesis [47], Multivariable Autoregressive Method [48], Sensitivity Function Approach [49], Sliding Mode Control [24,40] and Fuzzy Logic Control [50-51] have all been investigated. As ANNs have proved their potential in many non-linear parameter varying control systems, so it is appropriate to investigate their potential as a RRS controller for a non-linear ship model.

\section{NEURAL NETWORK BASED CONTROL}

Traditional autopilot designs are based on linearization of the vessel dynamics about an operating condition and designing the controller for that condition. Ship dynamics are not only nonlinear but they vary with a number of operating conditions such as the forward speed of the vessel, the depth of water, loading conditions and external disturbances (waves, ocean currents etc.). A conventional controller optimized for a particular condition may not give satisfactory performance for other operating conditions. It is possible to design a series of controllers 
about different operating conditions and then blending them together into a gain scheduled design. However, this procedure is time consuming and costly. Nonlinear techniques may also be used but they require accurate knowledge of the plant dynamics which may not be available. Moreover, design and tuning procedures involved in the non-linear controller design can present difficulties. Hence, there is a need of a controller which works in a robust manner at different operating conditions with minimum apriori knowledge of plant dynamics. An ANN controller is therefore, a good choice as it can perform optimally for varying operating conditions if trained properly. Moreover, it is a multivariable non-linear control system which does not require apriori understanding of the fundamentals of the plant under consideration. In this paper, an MLP network has been used as a RRS.

Since the pioneering work of Rumelhart and co-workers [52-53] much has been written about MLP networks and their applications. Almost every field of science and engineering has found successful applications of these networks. A comprehensive review reveals that in engineering applications of ANNs MLP networks have been used in more than $80 \%$ of the cases considered. These networks are trained by using the well-known error BP learning algorithm. The algorithm adjusts the weights and biases of an MLP network so as to minimize the sum of squared errors of the network. This is done by continually adjusting the values of the network weights and biases in the direction of steepest descent with respect to the error. The popularity of this algorithm itself is the main reason for the popularity of ANNs in general and MLP networks in particular.

The BP algorithm is based on supervised learning of ANNs. In such an approach an ANN is trained to behave like a specific form of a conventional controller. During the training phase, the same input is applied to the supervisor and to the ANN which is to be trained. The error between the output of the supervisor and the ANN is calculated, as shown in Fig. 1.

A cost function based on this error signal is minimized by using the error BP algorithm. Training is said to be successful when the error reaches to a pre-defined minimum value. More than one supervisor may be used to train a controller to perform multiple tasks. In this way, a single ANN controller will perform like multiple conventional controllers. In this paper, a single MLP controller is proposed which mimics the dynamics of two different supervisors. Details are presented in Section 5.

\section{RUDDER ROLL STABILIZATION SYSTEM}

The block diagram of a RRS system, as suggested by Fossen [22], is shown in Fig. 3, where $\Psi_{\mathrm{r}}, \Psi_{\mathrm{d}}$ and $\Psi$ denote the reference heading, desired heading and actual heading respectively. The variables $\phi_{\mathrm{r}}, \phi_{\mathrm{d}}$ and $\phi$ represent the reference roll angle, desired roll angle and actual roll angle respectively. The variable $\rho$ is the roll rate and $r$ is the yaw rate. The quantity $\delta_{h}$ is the output of the heading controller, $\delta_{\phi}$ is the output of roll controller and $\delta=\delta_{h}+\delta_{\phi}$ $\infty$ is the combined control output (i.e. the rudder angle). The different blocks of the closed loop system are described next.

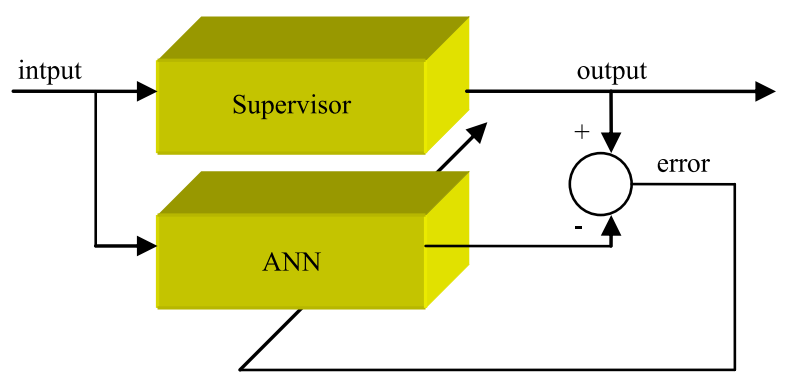

FIG. 1. TRAINING OF AN ANN CONTROLLER

Mehran University Research Journal of Engineering \& Technology, Volume 38, No. 2, April, 2019 [p-ISSN: 0254-7821, e-ISSN: 2413-7219] 


\subsection{Reference Model}

The primary purpose of a reference model is to generate desired behavior which is to be compared with the actual behavior of the system. In Fig. 2, reference model yields the desired heading for the heading controller. Typically, a second order model of the following form is used as a reference model [54-55]:

$G(s)=\frac{\omega_{n}^{2}}{s^{2}+2 \zeta \omega_{n} s+\omega_{n}^{2}}$

where $\zeta$ is the damping ratio and $\omega_{\mathrm{n}}$ is the undamped natural frequency in radian per seconds. In this study, $\zeta=$
0.8 and $\mathrm{w}_{\mathrm{n}}=0.15$ radians per second has been chosen for the heading subsystem. The desired roll angle has been assumed to be zero.

\subsection{Steering Machine}

The function of the steering machine is to move the rudder to a desired angular position when demanded by the control system or by the helmsmen. In this paper, a simplified model proposed by Van Amerongen [54] has been used and is shown in Fig. 3. For the container ship under consideration, an appropriate value of maximum rudder is $10^{\circ}$ and maximum rudder rate is $5^{\circ}$ second.

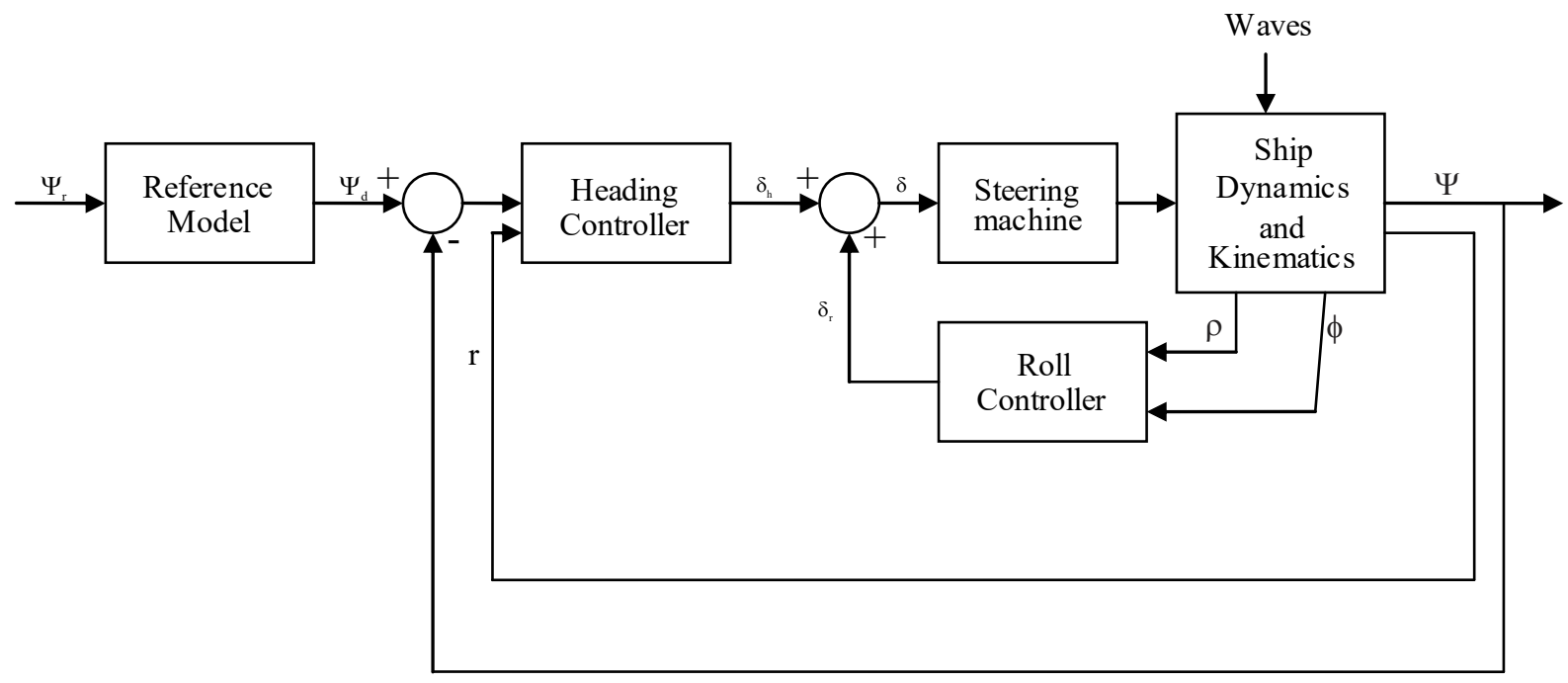

FIG. 2. GENERAL BLOCK DIAGRAM OF A RRS SYSTEM [22]

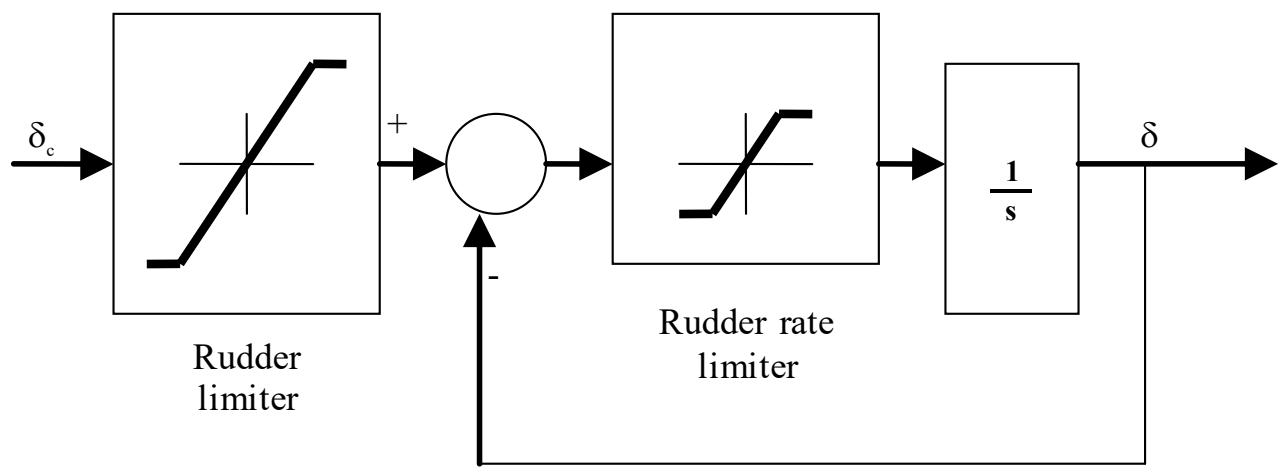

FIG. 3. STEERING MACHINE 


\subsection{Heading and Roll Controllers}

The heading controller (also known as the ship autopilot) is an automatic control system which manipulates the rudder to decrease the error between the reference heading angle and the actual heading angle. It can be designed for course keeping and/or course changing purposes. In other words, it is a steering controller. The objective of the roll controller, on the other hand, is to keep the roll motion as small as possible without degrading the performance of the heading controller. For an efficient RRS system, the heading bandwidth should be less than the roll bandwidth. As mentioned, the main purpose of this paper is to develop a multivariable neural network to perform tasks of both heading and roll controllers.

\subsection{Ship Model}

The model used in this paper represents a high speed container ship [22,56]. The main data of the ship are given in Table 1. In state-space form, the model can be represented as:

$\dot{x}=f(x, u)$

TABLE 1. MAIN DATA OF THE CONTAINER SHIP

\begin{tabular}{|c|c|}
\hline Length & $175.00 \mathrm{~m}$ \\
\hline Breadth & $25.40 \mathrm{~m}$ \\
\hline Draft fore & $8.00 \mathrm{~m}$ \\
\hline Aft & $9.00 \mathrm{~m}$ \\
\hline Mean & $8.50 \mathrm{~m}$ \\
\hline Displacement Volume & $21,222 \mathrm{~m}^{3}$ \\
\hline Height from keel to transverse metacenter & $10.39 \mathrm{~m}$ \\
\hline Height from keel to centre of buoyancy & $4.6154 \mathrm{~m}$ \\
\hline Block coefficient & 0.559 \\
\hline Rudder area & $33.0376 \mathrm{~m}^{2}$ \\
\hline Aspect ratio & 1.8219 \\
\hline Propeller diameter & $6.533 \mathrm{~m}$ \\
\hline
\end{tabular}

where $\mathbf{x}$ is the state vector and $\mathbf{u}$ represents the input to the ship. The state variables include the surge velocity $u$, sway velocity $\mathrm{v}$, yaw velocity $\mathrm{r}$, roll velocity $\mathrm{p}$, heading angle $\psi$ and roll angle $\phi$. The input is the rudder angle. The actual non-linear equations of motion and the values of hydrodynamic coefficients can be found in Fossen [22].

\subsection{Wave Model}

Sea waves have a profound impact on the motion of a ship. One major cause of ship capsizing is the abnormal roll motion due to waves [57]. It is therefore very important to ensure robustness of a controller during seakeeping. In this study, the Pierson-Markowitz [22,58] wave model has been used. This model describes a spectrum for fully developed wind generated seas and has the following form:

$S(\omega)=\frac{\alpha}{\omega^{5}} e^{-\beta / \omega^{4}}$

where $\alpha=8.1 \times 10^{-3} \mathrm{~g}^{2}$ and $\beta=0.74\left(\mathrm{~g} / \mathrm{v}_{19.4}\right)^{4} \cdot \mathrm{v}_{19.4}$ is the wind speed at a height of $19.4 \mathrm{~m}$ over the sea surface and $\mathrm{g}$ is the acceleration due to gravity (i.e. $9.8 \mathrm{~m} / \mathrm{s}^{2}$ ).

\section{DEVELOPMENT OF ANN CONTROLLER}

Conventionally, two separate controllers are designed, one as an autopilot (i.e. heading controller) and the other as a RRS $[22,24,41,59]$. The outputs of both the controllers are added to produce net control signal (i.e. rudder angle), as shown in Fig. 2. To minimize the coupling effects between roll and yaw dynamics, the well-known frequency separation method is used which ensures that the bandwidth of the heading subsystem is less than that of the roll subsystem. 
In this paper a single feedforward NN has been developed which behaves both as an autopilot as well as a roll stabilizer. For training of the controller two well optimized decoupled SM (Sliding Mode) controllers have been used as supervisors. One SM controller is a heading controller and the other one is a roll stabilizer. It has been ensured that the roll sub-system does not degrade the optimal performance of the heading sub-system.

Typically, a heading subsystem uses the state vector $\mathrm{x}_{\mathrm{h}}=$ $\left[\begin{array}{lll}\mathrm{v} & \mathrm{r} & \psi\end{array}\right]$ and a roll subsystem uses the state vector $\mathrm{x}_{\mathrm{r}}=[\mathrm{p}$ $\phi]$. These state vectors and the corresponding error signals have been generated using the two SM controllers and used as inputs to the proposed ANN controller. The output is the rudder angle. A three-layer MLP network has been trained with 15 neurons in the hidden layer and one neuron in the output layer. The activation function used in the hidden layer neurons is the tangent hyperbolic function. A linear transfer function has been used in the output neuron. The weights and biases of the ANN controller have been optimized by using the error BP learning algorithm with adaptive learning rate and momentum. Results are shown in Figs. 4-6 respectively. The manoeuvre being considered involves the ship a reference heading of $45^{\circ}$.

In these figures, the solid line and the dashed line represents the ANN controller and SM controller respectively.

Fig. 4 clearly indicates that both the ANN and SM controller turns the ship successfully without any overshoot. The corresponding heading rate is also satisfactory. Fig. 5 shows that the rudder response of both controllers during the turn is almost the same. Fig. 6 depicts the roll angle and roll rate in presence of wind generated waves. It can be seen that the performance of the proposed ANN controller provides improved roll stabilization when compared to the SM controller.
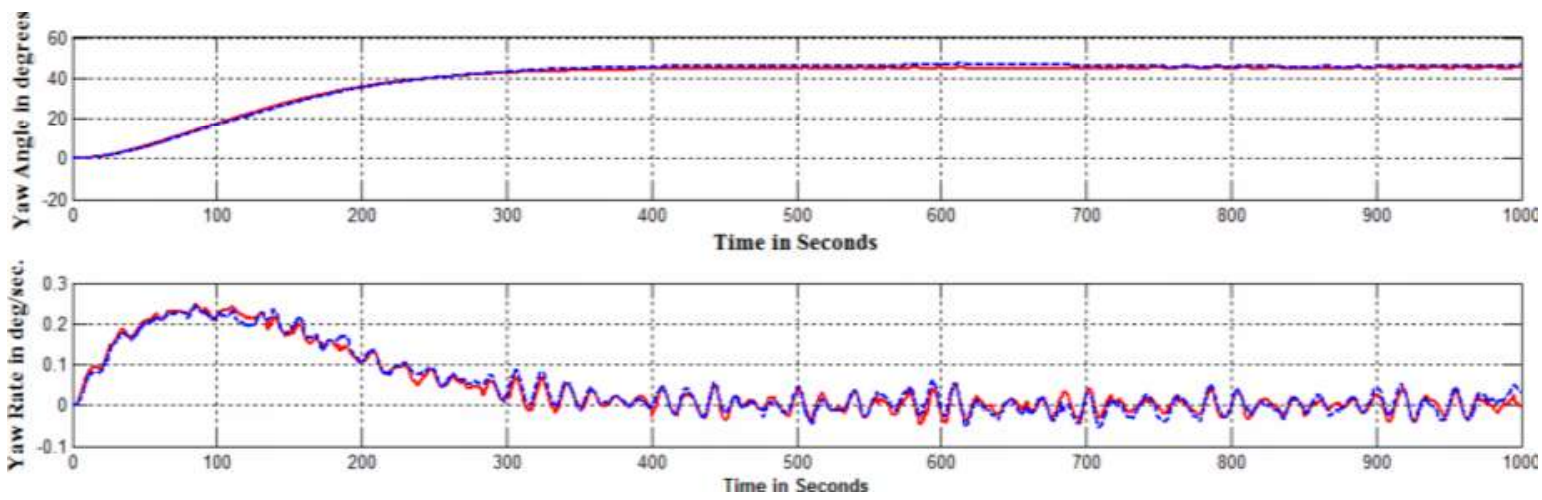

FIG. 4. HEADING (YAW) ANGLE AND YAW RATE OF ANN AND SM CONTROLLER

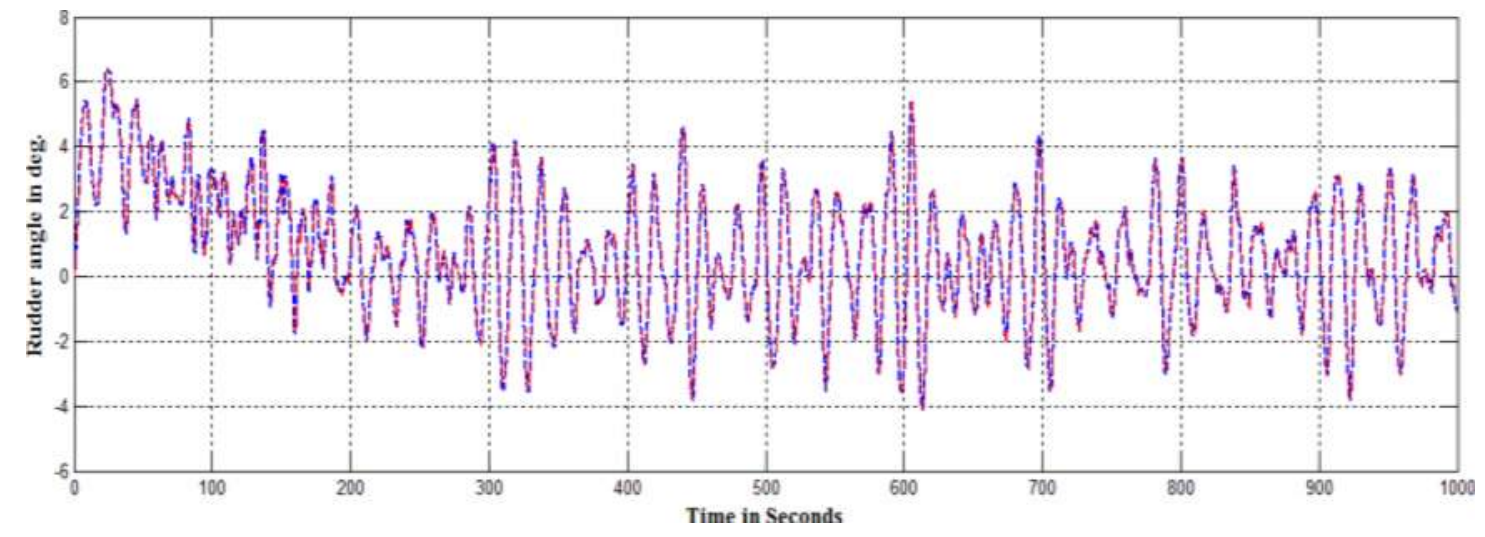

FIG. 5. RUDDER RESPONSE OF ANN (SOLID) AND SM (DASHED) 

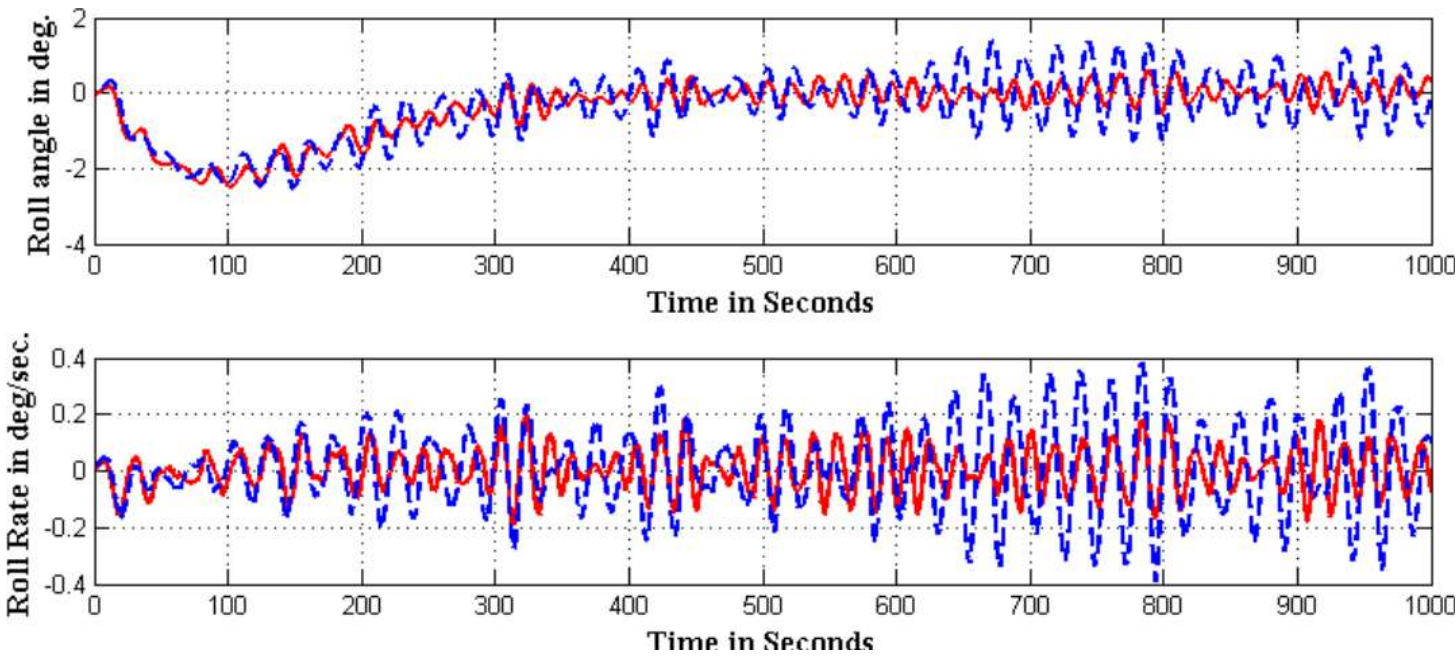

FIG. 6. ROLL ANGLE AND ROLL RATE

\section{CONCLUSION}

This paper has presented a NN based controller for RRS for a simulated container ship. A single ANN controller has been developed to behave both as a heading and a roll control system. Simulation results show that the controller has successfully captured the dynamics of the separate heading and roll controllers. The results are satisfactory and meet the performance requirements suggested for the combined system. In addition, the ANN has been shown to provide improved roll stabilization. Overall this study has shown that an ANN can be trained successfully to replace conventionally designed control systems.

\section{ACKNOWLEDGEMENT}

This work was jointly carried out at University of Glasgow, Scotland, UK, and Mehran University of Engineering \& Technology, Jamshoro, Pakistan. The facilities provided by the University of Glasgow and funding of the Higher Education Commission of Pakistan, are gratefully acknowledged. The authors declare that they have no conflict of interest.

\section{REFERENCES}

[1] Endo, M., Van Amerongen, J., and Bakkers, A.W.P., "Applicability of Neural Networks to Ship Steering", Proceedings of IFAC Workshop on Control Applications in Marine Systems, The Technical University of Lyngby, pp. 221-232, 1989.

[2] Pugh, G.A., "Ship Directional Control by Synthetic Neural Network", Proceedings of the American Control Conference, pp. 3028-3029, San Diego, USA, 1990.

[3] Richter, R., and Burns, R.S., "An Artificial Neural Network Autopilot for Small Vessels", Proceedings of United Kingdom Simulation Society, pp. 168-172, Edinburgh, 1993.

[4] Witt, N.A.J., Sutton, R., and Miller, K.M., "A Track Keeping Neural Network Controller for Ship Guidance", Proceedings of 3rd IFAC Workshop on Control Applications in Marine Systems, pp. 385-392, Trondheim, Norway, 1995.

[5] Burns, R.S., "The Use of Artificial Neural Networks for the Intelligent Optimal Control of Surface Ships", IEEE Journal of Oceanic Engineering, Volume 20, No. 1, pp. 65-72, 1995.

[6] Simensen, R., and Murray-Smith, D.J., "Ship Steering Control by Neural Networks Using Feedback Linearization Control Laws", Proceedings of IFAC/ IMACS International Workshop on Artificial Intelligence in Real Time Control, pp. 269-274, Bled, Slovenia, 1995. 
[7] Zhang, Y., Hearn, G.E., and Sen, P., "Neural Network Approach to Ship Track Keeping Control”, IEEE Journal of Oceanic Engineering, Volume 21, No. 4, pp. $513-527,1996$

[8] Unar, M.A., and Murray-Smith, D.J., "Radial Basis Function Networks for Ship Steering Control", Proceedings of $12^{\text {th }}$ International Conference on Systems Engineering,Volume 2, pp. 700-705, Coventry, UK, 1997.

[9] Unar, M.A., "Ship Steering Control Using Feedforward Neural Networks", Ph.D. Thesis, University of Glasgow, Glasgow, Scotland, 1999.

[10] Balicki, J., and Kitowski, Z., "Neural Genetic Techniques for Ship Control Systems", Proceedings of $2^{\text {nd }}$ International Conference on Marine Technology, Szczecin, Poland, 1997.

[11] Hardier, G., "Recurrent Neural Networks for Ship Modelling and Control", Proceedings of $11^{\text {th }}$ Ship Control Symposium, Southampton, Volume 1, pp. 39-61, UK, 1997.

[12] Pathan, D.M., Hussain, T., Daudpoto, J., and Memon, I.A., "Neural Network Steering Controller for a Ship, Sindh University Research Journal (Science Series), Volume 44, No.3, pp. 399-404, Jamshoro, Pakistan, 2012.

[13] Shen, H., and Guo, C., "Path Following Control of Underactuated Ships Using Actor Critic Reinforcement Learning with MLP Neural Networks", Proceedings of 6th International Conference on Information Science and Technology, pp. 317-321, 6-8 May, 2016.

[14] Renqiang, W., Yuelin, Z., and Jianming, S., “Application of Optimized RBF Neural Network in Ship's Autopilot Design”, Proceedings of IEEE Conference on Advanced Information Management, Communicates, Electronic and Automation Control, Xi'an, China,3-5 October, 2016.

[15] Li, Z., Hu, J., and Huo, X., "PID Control Based on RBF Neural Network for Ship Steering", Proceedings of World Congress on Information and Communication Technologies, Trivandrum, India, October 30November, 2, 2012.
[16] Xia, G., Wu, H., and Shao, X., “Adaptive Filtering Backstepping for Ships Steering Control Without Velocity Measurements and with Input Constraints", Mathematical Problems in Engineering, pp. 1-9, 2014

[17] Wang, N., Sun, J.C., Liu, Y.C., and Dai, B.J., "Dynamic Fuzzy Neural Control of Uncertain Surface Ships with Unknown Disturbances", Proceedings of 11th World Congress on Intelligent Control and Automation, pp. 4267-4272, Shenyang, China, June 29 - July 4, 2014

[18] Wang, N., Sun, J., Liu, Y., and Han, M., "Self Organizing Fuzzy Neural Tracking Control for Surface Ships with Unmodelled Dynamics and Unknown Disturbances", Proceedings of 33rd Chinese Control Conference, pp. 8859-8864, Nanjing, China, 28th-30th July, 2014.

[19] Cai, Y., Lv, Y., and Luo, H., "The Application of Fuzzy Neural Network in Ship Course Control System", Proceedings of $4^{\text {th }}$ International Workshop on Advanced Computational Intelligence, pp. 338-342, Wuhan China, 19th-21st October, 2011.

[20] Lauvdal, T., and Fossen, T.I., "Rudder Roll Stabilization of Ships Subject to Input Rate Saturation Using a Gain Scheduled Control Law", Proceedings of IFAC Conference on Control Applications in Marine Systems, Fukuoka, Japan, 27-30 October, 1998.

[21] Bhattacharyya, R., "Dynamics of Marine Vehicles", John Wiley and Sons, Ltd., New York, NY, 1978.

[22] Fossen, T.I., "Guidance and Control of Ocean Vehicles", John Wiley and Sons Ltd., New York, NY, 1994.

[23] Gawad, A.F.A., Ragab, S.A., Nayfeh, A.H., and Mook, D.T., "Roll Stabilization by Anti-Roll Passive Tanks", Ocean Engineering, Volume 28, pp. 457-469, 2001.

[24] Fang, M-C., and Luo, J-H., "On the Track Keeping and Roll Reduction of the Ship in Random Waves Using Different Sliding Mode Controllers", Ocean Engineering, Volume 34, pp. 479-488, 2007.

[25] Froude, W., "On the Rolling of Ships", Transactions of Institution of Naval Architects, Volume 2, 1861.

[26] Chadwick, J., "On the Stabilization of Roll", Transactions of Society of Naval Architects and Marine Engineers, Volume 63, pp. 234-280, 1955. 
[27] Taggart, R., “Anomalous Behavior of Merchant Ship Steering Systems”, Marine Technology, April, 1970.

Carley, J.B., and Duberley, A., "Design Considerations for Optimum Ship Motion Control”, Proceedings of $3^{\text {rd }}$ Ship Control Systems Symposium, Volume-C, Bath, UK, 1972 .

[29] Carley, J.B., "Feasibility Study of Steering and Stabilizing by Rudder", Proceedings of $4^{\text {th }}$ Ship Control System Symposium, The Hague, The Netherlands, 1975.

[30] Cowley, W.E., and Lambert, T.H., "Sea Trials on a Roll Stabilizer Using the Ship's Rudder", Proceedings of $4^{\text {th }}$ Ship Control System Symposium, Volume 2, The Hague, The Netherlands, 1975.

[31] Lloyd, A.E.J.M., "Roll Stabilization by Rudder", Proceedings of $4^{\text {th }}$ Ship Control System Symposium, The Hague, The Netherlands, 1975.

Baitis E., Woolaver, D.A., and Beck, T.A., "Rudder Roll Stabilization for Coast Guard Centres and Frigates", Naval Engineers Journal, pp. 267-282, 1983.

Van Amerongen, J., and Van Nauta, L., "Rudder Roll Stabilization: Controller Design Based on an Adaptive Criterion", Proceedings of American Control Conference, Volume 1, pp. 237-242, 1986.

[34] Van Amerongen, J., Van der Klugt, P.G.M., and Van Nauta Lemke, H.R., "Rudder Roll Stabilization for Ships", Automatica, Volume 26, No. 4, pp. 679-690, 1990.

[35] Kallstrom, C.G., "Improved Operational Effectiveness of Naval Ships by Rudder Roll Stabilization”, Proceedings of Asian Pacific Naval Exhibition and Conference, Singapore, 1987.

[36] Kallstrom, C.G., Wessel, P., and Sjolander, S., "Roll Reduction by Rudder Control", Transactions of Society of Naval Architects and Marine Engineers, Spring Meeting/STAR Symposium, pp. 67-76, Pittsberg, Pennsylvania, 1988.

[37] Blanke, M., Haals, P., and Andreasen, K.K., "Rudder Roll Damping Experience in Denmark", IFAC Workshop on Expert Systems and Signal Processing in Marine Automation, pp. 149-160, Lyngby, Denmark, 1989.
[38] Blanke, M., and Christensen, A., "Rudder-Roll Damping Autopilot Robustness due to Sway-Yaw-Roll Couplings", $10^{\text {th }}$ International Ship Control Systems Symposium, pp. A.93-A.119, Ottawa, Canada, 1993.

[39] Blanke M., Adrian, J., and Larsen, K.-E., "Rudder Roll Damping in Coastal Region Sea Conditions", Proceedings of $5^{\text {th }}$ IFAC Conference on Manoeuvring and Control of Marine Craft, pp. 39-44, 2000.

[40] Lauvdal, T., and Fossen, T.I., "Nonlinear Non-Minimum Phase Rudder Roll Damping System Using Sliding Mode Control", Proceedings of IFAC World Congress, San Francisco, 1996

[41] Lauvdal, T., and Fossen, T.I., "Rudder Roll Stabilization of Ships to Input Rate Saturation Using a Gain Scheduled Control Law", Proceedings of IFAC Conference on Control Applications in Marine Systems, pp. 111-116, Fukuoka, Japan, October, 1998

[42] Perez, T., "Ship Motion Control: Course Keeping and Roll Stabilization Using Rudder and Fins", Advances in Industrial Control, Springer Berlin Heidelberg, 2005.

[43] Undheim, S.M., "Rudder Roll Damping by $\mathrm{H}_{\infty}$ Control", M.Sc. Thesis, Department of Engineering Cybernetics, Norwegian University of Science and Technology, Trondheim, Norway, 2003.

[44] Saari, H., and Khichane, E., "Robust Rudder Roll Reduction of Container Ship", Journal of Automation and Systems Engineering, Volume 7, No. 3, pp. 94-104, 2013.

[45] Saari, H., and Ghannam, F., "Design of Container Ship Autopilot Using Robust Quantitative Feedback Theory”, Journal of Automation and Systems Engineering, Volume 9, No. 1, pp. 54-65, 2015.

[46] Perez, T., Tzeng, C-Y., and Goodwin, G.C., "Model Predictive Rudder Roll Stabilization Control for Ships", $5^{\text {th }}$ IFAC Maneuvering and Control of Marine Craft, Denmark, 2000

[47] Yang, C., and Blanke, M., "Rudder Roll Damping Controller Design Using $\mu$ Synthesis", Proceedings of IFAC International Conference on Control Applications in Marine Systems, pp. 117-122, 1998. 
[48] Oda, H., Ohtsu, K., and Hotta, T., "Statistical Analysis of a Rudder Roll Stabilization System”, Control Engineering Practice, Volume 4, No. 3, pp. 351-358, 1996.

[49] Tzeng, C.-Y., Wu, C.-Y., and Chu Y.-L., "A Sensitivity Function Approach to the Design of Rudder Roll Stabilization Controller", Journal of Marine Science and Technology, Volume 9, No. 2, pp. 100-112, 2001.

[50] Peng, X., Jia, S., and Yu, Y., "A Nonlinear Control Method Based on Fuzzy Optimization Algorithm for Rudder Roll Stabilization", Proceedings of 33rd Chinese Control Conference, pp. 7888-7891, Nanjing, China, 28th-30th July, 2014.

[51] Chen, S.-L., and Hsu, W.-C., "Fuzzy Sliding Mode Control for Ship Roll Stabilization", Asian Journal of Control, Volume 5, No. 2, pp. 187-194, June, 2003.

[52] Rumelhart, D.E., and McClelland, J.L., (Editors), "Parallel Distributed Processing: Explorations in the Microstructure of Cognition", Foundations, Volume 1, MIT Press, 1986.

[53] Rumelhart, D.E., and McClelland J.L. (Editors), "Parallel Distributed Processing: Explorations in the Microstructure of Cognition", Psychological and Biological Models, Volume 2, MIT Press, 1986.
[54] Van Amerongen, J., "Adaptive Steering of Ships-A Model Reference Approach to Improved Manoeuvringand Economical Course Keeping", Ph.D. Thesis, Delft University of Technology, The Netherlands, 1982.

[55] McGookin, E.W., Murray-Smith, D.J., Li, Y., and Fossen, T.I., "The Optimization of a Tanker Autopilot Control System Using Genetic Algorithms", Transactions of Institute of Measurement and Control, Volume 22, No. 2, pp. 141-178, 2000.

[56] Son, K.H., and Nomoto, K., "On the Coupled Motion of Steering and Rollingof a High Speed Container Ship", Naval Architect of Ocean Engineering,Volume 20, pp. 73-83, 1982.

[57] Vassalos, D., and Jasionowski, A., "Damaged Ship Hydrodynamics", Proceedings of $6^{\text {th }}$ International Ship Stability Workshop, Webb Institute, pp. 1-13, 2002.

[58] Pierson, W.J., and Moskowitz, L., "A Proposed Spectral form for Fully Developed Wind Seas Based on the Similarity Theory of SA Kitaigorodsku, US Naval Oceanographic Office Contract 62306-1042.

[59] Loo, M., "Inverse Model Based Controller for Marine Vessel Applications: A Comparison Study Against Other Control Methodologies", Ph.D. Thesis, University of Glasgow, Glasgow, Scotland, UK, 2005. 